\title{
Three New Lactobacillus plantarum Strains in the Probiotic Toolbox against Gut Pathogen Salmonella enterica Serotype Typhimurium
}

\author{
Mia Potočnjak ${ }^{1}$, Petra Pušić ${ }^{1}$, Jadranka Frece ${ }^{2}$, Maja Abram ${ }^{1}$, Tamara Janković ${ }^{1}$ \\ and Ivana Gobin ${ }^{1 *}$ \\ ${ }^{1}$ University of Rijeka, Faculty of Medicine, Department of Microbiology and Parasitology, \\ Braće Branchetta 20, HR-51000 Rijeka, Croatia \\ ${ }^{2}$ University of Zagreb, Faculty of Food Technology and Biotechnology, Laboratory for General \\ Microbiology and Food Microbiology, Pierottijeva 6, HR-10000 Zagreb, Croatia
}

Received: March 9, 2016

Accepted: November 23, 2016

\begin{abstract}
Summary
The benefits of probiotic bacteria have been widely explored. However, fermented foods and digestive system of humans and animals are an inexhaustible source of new potentially probiotic microorganisms. In this study we present three new Lactobacillus plantarum strains isolated from different dairy products: cow's cheese, sheep's cheese and whey. In order to determine the antibacterial activity of yet unexplored L. plantarum strains against Salmonella enterica serotype Typhimurium, in vitro competition and co-culture tests were done. Furthermore, adhesion of these strains to Caco-2 cells and their influence on the adhesion of Salmonella were tested. Results showed the potential probiotic activity of isolated strains. L. plantarum strains survived in the presence of $1 \%$ bile salts, they possessed acidification ability, antibacterial activity and significantly attenuated the growth of $S$. Typhimurium in brain heart infusion broth. All tested L. plantarum strains were able to adhere to Caco-2 cells and significantly impair the adhesion of $S$. Typhimurium. All three L. plantarum strains exhibited significant probiotic potential and anti-Salmonella activity; therefore, further testing on in vivo models should follow.
\end{abstract}

Key words: probiotic bacteria, antagonistic activity, Salmonella, mechanism of action

\section{Introduction}

Probiotic microorganisms are extensively studied and implemented in a wide range of applications such as prevention of food poisoning or treatment of certain gastrointestinal disorders (1-4). They are defined as live microorganisms which when administered in adequate amounts confer a health benefit on the host (5). One of the most frequent functional properties for probiotics concerns the putative reduction and prevention of infectious disease in the gastrointestinal tract $(1,2)$. Human gastrointestinal tract houses countless bacterial species (6) and beneficial role of intestinal microbiota is still intensively investigated. Probiotic microorganisms react to intestinal pathogens by producing antibacterial compounds such as organic acids, hydrogen peroxide, diacetyl, bacteriocins and antimicrobial peptides, with a variable spectrum of action $(7,8)$. They can induce changes in enzyme activity, compete for nutrients and adhesion sites and/or increase levels of antibody and macrophage activity (9).

While selecting a preferable probiotic strain several aspects of functionality have to be considered such as tolerance to human gastric juice and bile tolerance as an im- 
portant property for survival in the small bowel (10). Another important criterion for selecting probiotic strains is adherence to intestinal epithelium. This is a crucial step in colonisation of the gastrointestinal tract and is important for competitive exclusion of enteropathogens $(11,12)$. An important feature is also antagonistic activity against gut pathogens such as Helicobacter pylori, Salmonella spp., Listeria monocytogenes and Clostridium difficile (13-15).

Salmonella enterica serotype Typhimurium (S. Typhimurium), belonging to the diverse Salmonella genus, is one of the leading causes of self-limiting non-typhoidal gastroenteritis in humans. Most infections arise from oral ingestion of contaminated food or water $(16,17)$. Adhesion to mammalian epithelial cells is a crucial step for bacteria to colonise the gastrointestinal tract. Epithelial cells of gastrointestinal tract are protected from pathogenic bacteria by several mechanisms exerted by commensal microbiota: competition for adhesion sites, and production of components with antimicrobial activity $(18,19)$. The initial step of adhesion of Salmonella spp. is mediated by bacterial fimbriae which recognise certain receptors on eukaryotic cells (20). Salmonella enterica is known to adhere to and invade intestinal cells, including Caco-2 cells (21). Several studies indicate that different Lactobacillus strains could inhibit the adhesion of Salmonella and some other diarrhoeagenic bacteria (Escherichia coli, Yersinia pseudotuberculosis and Listeria monocytogenes), thus reducing colonisation and preventing infection $(22,23)$.

The most commonly used probiotic microorganisms include various species of genera Lactobacillus and Bifidobacterium (24). Bacteria in genus Lactobacillus are aero-tolerant anaerobic, catalase-negative, rod-shaped lactic acid bacteria. Several strains of the genus Lactobacillus possess probiotic properties. The production of lactic acid together with some other products, like bacteriocins is responsible for the antimicrobial activity of these bacteria $(25,26)$.

The objective of the present study is to test the effect of three potentially probiotic Lactobacillus plantarum strains isolated from traditional dairy products against the gut pathogen Salmonella enterica serotype Typhimurium.

Identification of L. plantarum strains was performed by classical biochemical and microbiological methods. Furthermore, viability of strains in the presence of bile salts, acidification ability, antimicrobial and anti-adhesion activity were examined.

\section{Materials and Methods}

\section{Bacterial strains and growth conditions}

Three Lactobacillus plantarum isolates (strain A isolated from homemade cow's cheese, strain B from homemade sheep's cheese and strain S1 from whey), L. plantarum ATCC 1804 and clinical isolate of Salmonella enterica serotype Typhimurium 3064 were obtained from the culture collection of Faculty of Food Technology and Biotechnology, University of Zagreb, Croatia. All tested bacteria were stored at $-80{ }^{\circ} \mathrm{C}$ in $30 \%$ glycerol broth.
Lactobacilli were grown in de Man, Rogosa and Sharpe (MRS) broth (Biolife Italiana Srl, Milan, Italy) in microaerophilic atmosphere $\left(5 \% \mathrm{CO}_{2}\right)$ for $24 \mathrm{~h}$ at $37^{\circ} \mathrm{C}$. A culture of $S$. Typhimurium was prepared in nutrient or brain heart infusion (BHI) broth (Biolife Italiana Srl), and the number of bacteria was determined by plate counting on Salmonella Shigella (SS) agar (Biolife Italiana Srl) or Luria-Bertani (LB) agar (Biolife Italiana Srl). The number of bacteria in the inoculum was determined photometrically at $\lambda=600 \mathrm{~nm}$ and the absorbance $(A)$ was set to 1 , coresponding to a concentration of $10^{9} \mathrm{CFU} / \mathrm{mL}$.

\section{Human intestinal cells}

In order to examine bacterial adhesion to human intestinal cells, human colon adenocarcinoma cell line Caco-2 was used. Caco-2 cells were cultured in liquid nutrient Dulbecco's Modified Eagle medium (DMEM; Lonza Group Ltd., Verviers, Belgium) suplemented with $10 \%$ foetal calf serum (FCS), $2 \mathrm{mmol} / \mathrm{L}$ of L-glutamine, $100 \mathrm{U} /$ $\mathrm{mL}$ of penicillin and $100 \mu \mathrm{g} / \mathrm{mL}$ of streptomycin (Lonza Group Ltd.), at $37{ }^{\circ} \mathrm{C}$ in the $\mathrm{CO}_{2}$ incubator MCO-20AC (Sanyo, Osaka, Japan). For the adherence assays, Caco-2 monolayers were prepared in 24-well tissue culture plates (TPP, Trasadingen, Switzerland). Cells were seeded at concentration of $2.5 \cdot 10^{5}$ cells $/ \mathrm{mL}$ and incubated until the confluence was obtained. The culture medium was replaced by DMEM without any supplements at least $1 \mathrm{~h}$ prior to the adhesion experiments.

\section{Characterisation of potential probiotic strains}

\section{MALDI-TOF MS analysis}

Matrix-assisted laser desorption/ionisation time-of-flight mass spectrometer (MALDI-TOF MS; Bruker Daltonik $\mathrm{GmbH}$, Bremen, Germany) was used for identification of potential probiotic strains after biochemical identification by API test (bioMérieux, Marcy l'Etoile, France). Samples were prepared according to the manufacturer's recommendation using a Microflex $\mathrm{LT}^{\mathrm{TM}}$ instrument (Bruker Daltonik). For the identification, the peaks from the generated mass spectrum were compared with reference spectra of the integrated database using MALDI Biotyper software package (Bruker Daltonik $\mathrm{GmbH}$ ).

\section{Viability of the cells in the presence of bile salts}

Resistance to bile salts was tested according to Babic et al. (3). Briefly, BHI broth was prepared by the addition of $1 \%$ (mass per volume) of bile salts (LP0055; Oxoid LTD, Basingstoke, UK). Overnight bacterial cultures were adjusted to initial $A_{600 \mathrm{~nm}}=0.2$ in $\mathrm{BHI}$ broth with bile salts. After incubation with agitation at $37^{\circ} \mathrm{C}$ for $24 \mathrm{~h}$, bacterial growth was measured using a photometer (Biophotometer, Eppendorf, Hamburg, Germany) at $\lambda=600 \mathrm{~nm}$.

\section{The acidification ability of Lacobacillus isolates}

The ability of the isolates to reduce the $\mathrm{pH}$ of the medium was tested by overnight incubation of cultures at 37 ${ }^{\circ} \mathrm{C}$ with agitation in BHI and MRS broths, as well as in $\mathrm{BHI}$ broth with $1 \%$ bile salts. Initial $\mathrm{pH}$ of the media was 7.2 (BHI broth), 6.5 (MRS broth) or 7.2 (BHI broth with 1 $\%$ bile salts). 


\section{Functional characterisation of Lacobacillus isolates}

Agar well diffusion assay

Antibacterial activity of cell-free culture supernatants (CFS) of L. plantarum strains was examined by the agar well diffusion assay as described by Bilkova et al. (27). Culture supernatants were prepared by cultivation of lactobacilli in MRS broth overnight at $37{ }^{\circ} \mathrm{C}$ in microaerophilic atmosphere $\left(5 \% \mathrm{CO}_{2}\right)$ and the cells were removed by centrifugation at $2000 \times g$ for $10 \mathrm{~min}$. The supernatants were sterile-filtered through mixed cellulose ester membrane filter with $0.22-\mu \mathrm{m}$ pores (Merck, Darmstadt, Germany). The equal fractions of the supernatant were adjusted to neutral $\mathrm{pH}=7.0$ by adding $1 \mathrm{M} \mathrm{NaOH}$ and/or heat treated $\left(5 \mathrm{~min}\right.$ at $\left.100^{\circ} \mathrm{C}\right)$. S. Typhimurium was diluted in physiological saline (McFarland No. 1; Densimat, bioMérieux) and spread on the surface of Müller Hinton (MH) agar (Oxoid Ltd.). After absorption wells of $5 \mathrm{~mm}$ in diameter were made with a sterile cork borer, portions of $50 \mu \mathrm{L}$ of each untreated and treated CFS were added. The plates were left undisturbed for two hours and incubated for $24 \mathrm{~h}$ at $37^{\circ} \mathrm{C}$, when the inhibition zones were measured.

\section{Co-culture assay}

Co-culture assay is a method for determination of antimicrobial effect of probiotic lactobacilli (28). Bacteria, $10^{5}$ $\mathrm{CFU} / \mathrm{mL}$ of Lactobacillus and $10^{4} \mathrm{CFU} / \mathrm{mL}$ of $S$. Typhimurium (a ratio of 10:1), were co-incubated in BHI broth for 24 $\mathrm{h}$ at $37^{\circ} \mathrm{C}$. The control was the monoculture of $S$. Typhimurium. The number of Salmonella was determined by plate counting on LB agar. Experiments were carried out in triplicates. The inhibition was calculated using the following equation:

$$
\text { Inhibition }=\left(\frac{\left(\frac{N(\text { bacteria })}{V(\text { control })}\right)-\left(\frac{N(\text { bacteria })}{V(\text { co-culture })}\right)}{\left(\frac{N(\text { bacteria })}{V(\text { control })}\right)}\right) \cdot 100
$$

\section{Adhesion assay}

Adhesion of L. plantarum strains to Caco-2 cells

The adhesion of tested Lactobacillus strains was examined by adding bacterial suspension $\left(10^{8} \mathrm{CFU}\right.$ per well) to Caco-2 monolayers at the multiplicity of infection (MOI) of 1:1000. Each plate with Caco-2 cells was centrifuged at $240 \times g$ for $5 \mathrm{~min}$, followed by $2 \mathrm{~h}$ of incubation at $37^{\circ} \mathrm{C}$. After the incubation, the Caco- 2 monolayers were washed three times with sterile phosphate-buffered saline (PBS) $(\mathrm{pH}=7.2)$ and treated with $0.05 \%$ Triton X-100 (Sigma-Aldrich Chemie $\mathrm{GmbH}$, Taufkirchen, Germany). The number of bacteria was determined by plating 10-fold dilution on MRS agar. For quantitative assessment of the adhesion, Caco- 2 cells were added to 24 -well plates with sterile cover slips and incubated for $2 \mathrm{~h}$ for cell attachment. Furthermore, Caco- 2 cells were infected under previously described conditions and after $2 \mathrm{~h}$ of incubation the monolayers were washed three times with sterile PBS $(\mathrm{pH}=7.2)$, fixed with methanol and stained with Giemsa stain (Sigma-Aldrich Chemie $\mathrm{GmbH}$ ) and examined microscopically (model IX51; Olympus, Tokyo, Japan). Each adherence assay was conducted in triplicate, and the number of adherent bacteria was counted on about 100 Caco-2 cells in randomly selected microscopic fields.
The effect of L. plantarum strains on Salmonella adhesion to Caco-2 cells

To study the effect of the tested lactobacilli on Salmonella adhesion, exclusion and competition assays were used. For the pretreatment experiment (exclusion assay) suspensions of lactobacilli $\left(10^{8} \mathrm{CFU}\right.$ per well) were added on monolayers of Caco- 2 cells in antibiotic-free DMEM medium with $10 \%$ of FCS. The plates were then centrifuged at $240 \times g$ for $5 \mathrm{~min}$ to allow the probiotic bacteria to adhere to the cells and incubated for $2 \mathrm{~h}$ at $37^{\circ} \mathrm{C}$ in atmosphere with $5 \% \mathrm{CO}_{2}$. The success of the adherence was observed using inverted microscope (model IX51; Olympus). Upon completion of the incubation period, the monolayers of Caco-2 cells were washed three times with sterile PBS and the Salmonella suspension $\left(10^{6} \mathrm{CFU}\right.$ per well) in antibiotic-free DMEM with $10 \%$ FCS was added and incubated for additional $2 \mathrm{~h}$. For the co-incubation (competition assay), L. plantarum strains and Salmonella $\left(10^{8} \mathrm{CFU}\right.$ per well and $10^{6} \mathrm{CFU}$ per well in antibiotic-free DMEM with $10 \%$ of FCS, respectively) were added to Caco-2 cells and incubated for $2 \mathrm{~h}$. At the end of both experiments, the cells were washed three times in PBS to remove any unattached bacteria and treated with $0.05 \%$ Triton X-100. The number of bacteria was determined by plating the 10-fold dilution on LB agar. The Trypan Blue (Sigma-Aldrich Chemie $\mathrm{GmbH}$ ) test was used to examine the Caco-2 cell viability throughout the adhesion studies.

\section{Statistical analysis}

The data were analysed using STATISTICA commercial software, v. 12.0 (StatSoft, Tulsa, OK, USA). Results are expressed as mean value \pm standard deviation (S.D.). Normality of the data distribution was assessed by the Kolmogorov-Smirnov normality test. The distribution qualified the normality test, so nonparametric tests were applied. Differences between groups of samples were analysed by the Kruskal-Wallis ANOVA on ranks test, while the influence of L. plantarum strains on Salmonella Typhimurium was tested by Mann-Whitney U test. Differences with $p<0.05$ were considered to be statistically significant.

\section{Results}

\section{General characterisation of L. plantarum strains}

Observed carbohydrate fermentation patterns confirmed the species identification according to the API system database with 99.5-99.9\% ID similarity (data not shown). MALDI-TOF MS analysis presented specific spectra allowing discrimination between closely related species and classification at subspecies level. Comparability of the match to the reference is expressed from 0 (no match) to 1000 (perfect identity) and converted into log score in the range of $0-3$. L. plantarum A strain gave scores of 2.443 , L. plantarum B strain of 2.448 and L. plantarum S1 strain of 2.403. Applying the recommended criteria, score $\geq 2.3$ indicates highly probable L. plantarum species identification.

All tested lactobacilli were capable of growing in BHI broth containing $1 \%$ bile salts, despite the lower growth 
rate than the growth in plain BHI broth. All three L. plantarum strains were able to reduce $\mathrm{pH}$ in the $\mathrm{BHI}$ and MRS broths to $\mathrm{pH}$ of approx. 4 . The strains were also metabolically active in BHI broth with $1 \%$ bile salts, reducing the $\mathrm{pH}$ to around 6.0 , compared to control BHI where $\mathrm{pH}$ was adjusted to 7.2 (Table 1 ).

Table 1. Growth characteristics of Lactobacillus plantarum isolates

\begin{tabular}{lcccc}
\hline \multirow{2}{*}{ Lactobacillus plantarum } & \multicolumn{3}{c}{$A_{600 \mathrm{~nm}}$} \\
\cline { 2 - 5 } & Strain A & Strain B & Strain S1 \\
\hline BHI broth & 5.87 & 4.73 & 5.97 \\
BHI broth + 1 \% bile salts & $1.5^{*}$ & $2.14^{*}$ & $3.59^{*}$ \\
\hline \multicolumn{2}{r}{ Initial pH } & \multicolumn{3}{c}{ Medium pH after $24 \mathrm{~h}$} \\
\hline BHI broth & 7.2 & $(4.2 \pm 0.1)^{*}$ & $(4.1 \pm 0.1)^{*}$ & $(4.1 \pm 0.1)^{*}$ \\
MRS broth & 6.5 & $(3.9 \pm 0.1)^{*}$ & $(3.9 \pm 0.1)^{*}$ & $(3.9 \pm 0.1)^{*}$ \\
BHI broth + & 7.2 & $6.1 \pm 0.1$ & $6.1 \pm 0.1$ & $6.1 \pm 0.1$ \\
1\% bile salts & & & & \\
\hline
\end{tabular}

Asterisk indicates differences between strains A, B and S1 and the control at $\mathrm{p}<0.05$

\section{Functional characterisation of L. plantarum strains}

The antibacterial effect of CFS of each L. plantarum strain on the $S$. Typhimurium was tested by the agar well diffusion assay. There were no differences in the diameter of growth inhibition zones among the tested Lactobacillus strains and all strains showed anti-Salmonella activity (Table 2). Moreover, the antibacterial activity of CFS was evaluated after neutralisation to $\mathrm{pH}=7.0$ and heat treatment. Neutralisation of the $\mathrm{pH}$ resulted in a complete loss of antibacterial activity of lactobacilli, while heat treatment had almost no impact on the inhibitory effect of CFS (Table 2).

Furthermore, the effect of L. plantarum strains on $S$. Typhimurium growth in BHI was examined. All tested $L$. plantarum strains inhibited $S$. Typhimurium growth $(\mathrm{p}<$ $0.05)$ at all time points $(6,12$ and $24 \mathrm{~h})$ in co-culture assay in BHI broth and there were no statistically significant differences among the strains (Fig. 1). After $24 \mathrm{~h}$ of co-cultivation, the number of Salmonella cells was reduced 1000 times in comparison with Salmonella monoculture. The inhibition was most pronounced after $12 \mathrm{~h}$ of co-incubation and amounted to 97,98 and $94 \%$ by strains A, B and S1, respectively.

Table 2. Antibacterial activity of the cell-free supernatants (CFS) of Lactobacillus plantarum strains against $S$. Typhimurium

\begin{tabular}{|c|c|c|c|}
\hline \multirow{3}{*}{ Treatment } & \multicolumn{3}{|c|}{ L. plantarum CFS } \\
\hline & Strain A & Strain B & Strain S1 \\
\hline & \multicolumn{3}{|c|}{ Zone of inhibition/mm } \\
\hline untreated & $8.0 \pm 1.0$ & $8.6 \pm 0.6$ & $8.3 \pm 0.6$ \\
\hline $\mathrm{pH}=7.0$ & $5.0 \pm 0.0$ & $5.0 \pm 0.0$ & $5.0 \pm 0.0$ \\
\hline $\begin{array}{l}\text { heat treatment } \\
\left(5 \mathrm{~min} \text { at } 100^{\circ} \mathrm{C}\right)\end{array}$ & $7.6 \pm 0.6$ & $8.3 \pm 0.6$ & $8.0 \pm 0.0$ \\
\hline
\end{tabular}

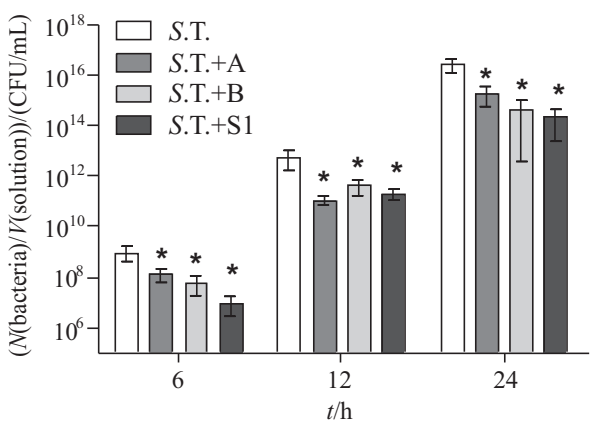

Fig. 1. The inhibitory activity of Lactobacillus plantarum strains A, B and S1 co-cultured with Salmonella Typhimurium (S.T.). Values are mean \pm standard deviations of the results from two separate experiments. Asterisk indicates differences between S.T.+A, S.T.+B and S.T. + S1 and the control at $\mathrm{p}<0.05$

The adhesive properties of L. plantarum strains were examined on human enterocyte cell line, Caco- 2 cells. The results showed that after $2 \mathrm{~h}$, strains $\mathrm{A}$ and $\mathrm{S} 1$ showed higher adhesion ability to Caco-2 cells (approx. $10^{5}$ and $10^{4} \mathrm{CFU} / \mathrm{mL}$, respectively), than strain $\mathrm{B}\left(10^{3} \mathrm{CFU} / \mathrm{mL}\right)$ (Fig. 2). The number of adhered L. plantarum strains A and S1 per eukaryotic cell was 5 to 10 , and of strain B 1 to 5 (Fig. 2).
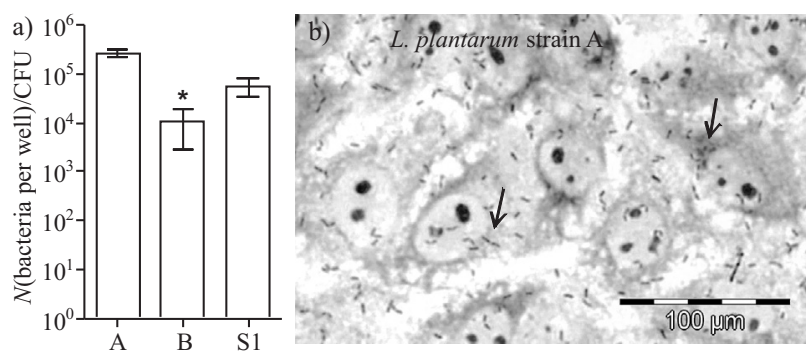

Fig. 2. Adhesion properties of Lactobacillus plantarum: a) adhesion of strains A, B and S1 to Caco-2 cells. Values are mean \pm standard deviation of the results from two separate experiments. Asterisk indicates differences between the tested groups at $\mathrm{p}<0.05 ; \mathrm{b}$ ) microphotographs (magnification of $1000 \times$ ) show adhesion of L. plantarum strain A to the Caco-2 cells (arrows). Slides were stained with Giemsa stain

The same model was used to test the adhesion of pretreated $S$. Typhimurium or simultaneously incubated $S$. Typhimurium with Lactobacillus strains to Caco-2 cells. Results indicated that the pretreatment of L. plantarum strain A ( $p=0.0045)$ and strain S1 ( $=0.0067)$ significantly reduced the adhesion of Salmonella cells to Caco-2 cells (Fig. 3), where the strain S1 was the most effective. The number of adhered Salmonella after $2 \mathrm{~h}$ of simultaneous incubation with all L. plantarum strains was significantly lower than the number of Salmonella cells alone. There were no differences among L. plantarum strains (Fig. 3). The comparison of the influence of Lactobacillus strains in pretreatment and in simultaneous incubation with $S$. Typhimurium showed that the simultaneous incubation with strain B was the most effective in the inhibition of Salmonella adhesion to Caco-2 cells. 


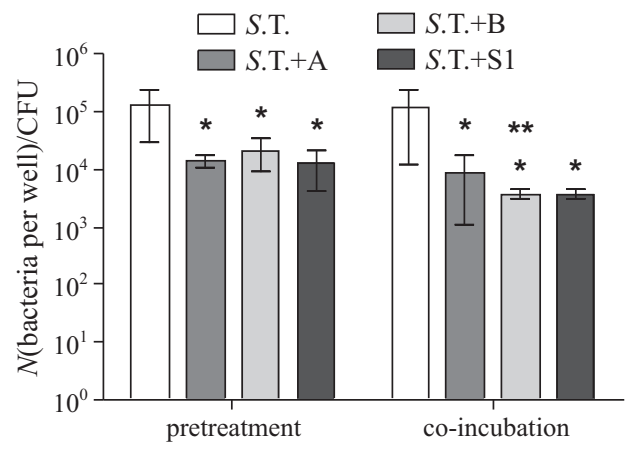

Fig. 3. Number of Salmonella Typhimurium (S.T.) bacteria adhered to Caco-2 cells, depending on the pretreatment and the simultaneous incubation with L. plantarum strains A, B and S1 (co-incubation) during $2 \mathrm{~h}$ of incubation. Mean values \pm standard deviations of at least three independent experiments are shown. Single asterisk indicates differences between S.T.+A, S.T.+B and S.T.+S1 and the control (S.T.), and two asterisks indicate differences among treated groups (S.T.+B) by ANOVA on ranks test at $\mathrm{p}<0.05$

\section{Discussion}

Several representatives of Lactobacillus genus including L. plantarum species were found to exhibit probiotic activity (29). Many traditional lactic acid-fermented foods, dominantly dairy products are considered as ideal carriers for probiotic bacteria $(5,30)$. Additionally, traditional dairy products may also be used as an ideal source for the isolation of novel probiotic lactic acid bacteria (2). However, as these bacterial strains differ in their characteristics, it is necessary to thoroughly examine their functional properties including antimicrobial activity and persistence in the gastrointestinal tract with reference to their ability to adhere to epithelial cells (31). In this study of relevant functional characteristics of three new L. plantarum strains (A, B and S1) and their activity against gut pathogen $S$. Typhimurium were evaluated in order to determine their probiotic potential. Candidate strains are supposed to meet the safety rules as they originate from popular types of traditional dairy products (strain A from homemade cow's cheese, B from homemade sheep's cheese and S1 from whey), which are commonly and widely used for food. Biochemical and phenotypic characterisation were performed confirming these are three different isolates of the same species of L. plantarum.

All three strains demonstrated the ability to reduce $\mathrm{pH}$ of different media, and were able to grow in the presence of bile salts. Lactobacilli ferment carbohydrates and produce high concentrations of lactic acid, which decreases the $\mathrm{pH}$ of their environment and enhances antimicrobial effectiveness (26).

Resistance to bile salts was evaluated under the conditions which mimic those in the gastrointestinal tract. Bacteria that are tolerant to bile salts are more promising as probiotic candidates, because it enables them to survive in the environment of small intestine (32).

In order to categorise certain bacteria as a probiotic, it is also necessary to exhibit antagonistic effect against pathogenic bacteria and adhesion to the intestinal epithelium. Since Salmonella is one of the frequent causes of infection of the digestive tract (33), we decided to use it as a test microorganism for antibacterial properties of our potentially probiotic bacteria. Salmonella species are facultative intracellular bacteria, capable of invading, surviving, and often multiplying within diverse eukaryotic cell types, including epithelial and phagocytic cells (21). Adhesion to the intestinal epithelial surface is a key step in pathogenesis and is central to colonisation of the intestine $(34,35)$.

The antimicrobial effect of CFS of all three L. plantarum strains against $S$. Typhimurium was first shown by well diffusion method, and the zone of inhibition ranged from 8.0 to $8.6 \mathrm{~mm}$. The complete loss of their antibacterial activity was determined after neutralisation of $\mathrm{pH}$, suggesting that the organic acids produced during fermentation were most probably responsible for the inhibitory effect. Furthermore, the significant acidification of the medium ( $\mathrm{pH} \approx 4.0$ ) occurred after $24 \mathrm{~h}$ of incubation of $L$. plantarum strains in $\mathrm{BHI}$ broth. It seems that low $\mathrm{pH}$ of Lactobacillus CFS is most likely responsible for the inhibition of $S$. Typhymurium growth. The antimicrobial effect of organic acids has been observed when using several Lactobacillus species $(26,36)$. The growth-inhibiting activity of different probiotic bacteria against pathogens such as Gram-negative S. Typhimurium, E. coli or Campylobacter jejuni, and Gram-positive bacteria Enterococcus faecalis and Clostridium difficile was attributed to a $\mathrm{pH}$ reduction and/or to the production of organic acids (37). According to Millette et al. (38) antimicrobial effect of lactobacilli in co-culture with pathogenic bacteria is mainly due to production of organic acids, which results in $\mathrm{pH}$ reduction, although they can produce some other substances as well.

The capability of L. plantarum isolates to inhibit the growth of Salmonella was evaluated in co-cultivation experiments in vitro. An inhibitory effect of all tested $L$. plantarum strains, regardless of the length of incubation, was shown. The results of the present study indicate that the inhibitory activity of all three Lactobacillus strains was mostly due to the $\mathrm{pH}$ effect, which is even more pronounced in Salmonella because they are sensitive to low $\mathrm{pH}$. Besides the production of different inhibitory molecules during co-cultivation, lactobacilli have the ability to coaggregate with numerous pathogens, inhibiting the overgrowth and proliferation of pathogenic microorganisms (39). We have previously shown that the same three strains of L. plantarum are capable of high autoaggregation $(\geq 80 \%)$ and marked coaggregation with different enteropathogens including S. Typhimurium (around $20 \%$ ) (40). It can be assumed that due to very close proximity of both bacteria, antimicrobial substances released by lactobacilli can directly inhibit Salmonella.

Further important characteristics of probiotics are their own adherence to intestinal epithelial cells, as well as the prevention of the adhesion of pathogenic bacteria $(41,42)$. Adherence of probiotic bacteria to the intestinal epithelium is an important characteristic as it promotes colonisation and long-time persistence. Our results showed that all strains were capable of adhering to Caco-2 cells, although L. plantarum strains A and S1 had better adhesive properties.

To test the influence of lactobacili on Salmonella adhesion to Caco- 2 cells, two types of experiments were done: pretreatment (L. plantarum was incubated with Caco-2 cells first, and then Salmonella was added), and co-incuba- 
tion (both bacteria were added to Caco-2 cells simultaneously). In order to exclude the influence of the $\mathrm{pH}$, to which Caco- 2 cells are extremely sensitive, bacteria were prepared in DMEM medium supplemented with $10 \%$ FCS. The $\mathrm{pH}$ of the DMEM medium was monitored during each experiment and it was stable (7.2-7.5). Also, the viability of Caco-2 cells was tested during experiments and the percentage of survival was over $90 \%$ (data not shown). The results showed that all Lactobacillus strains interfered with $S$. Typhimurium adhesion to Caco-2 cells regardless of whether the Caco-2 cell were pretreated or co-incubated with the tested strains. Most probably Lactobacillus, similarly to Salmonella, uses receptor-type adhesion mechanism on Caco-2 cells and thus significantly attenuates its adhesion. The number of adhered Salmonella in the presence of any of the three Lactobacillus strains was significantly lower after the pretreatment (approx. 10 CFU per well) or after co-incubation (approx. $10^{3} \mathrm{CFU} /$ well) than the number of Salmonella alone (approx. $10^{5}$ CFU per well)

Jankowska et al. (43) have shown that the presence of L. paracasei affected S. enterica adhesion to Caco-2 cells (4-fold reduction), but the anti-adhesion activity was even more pronounced (8-fold) when L. paracasei was preincubated with Caco- 2 cells prior to Salmonella addition. In the same study, Lactobacillus spent culture supernatants (SCS) acted as weaker inhibitors of Salmonella adhesion. In contrast, Lehto and Salminen (26) showed that only SCS of Lactobacillus strain GG, and not bacteria alone inhibited the adhesion of $S$. Typhimurium to Caco-2 cells and that the inhibition of SCS was most likely because of low $\mathrm{pH}$. In our study, the influence of SCS of L. plantarum strains was not further tested because of the weak viability of Caco-2 cells in a preliminary experiment. We can postulate that inhibition of Salmonella adherence by all three Lactobacillus strains was because of the competition for eukaryotic cell receptors, although it may also involve some of produced or secreted antimicrobial compounds.

\section{Conclusion}

The results presented in this study demonstrated that all three Lactobacillus plantarum strains obtained from traditional dairy products exhibited favourable probiotic characteristics like the ability to grow in the presence of bile salts and good adhesion to Caco-2 cells, as well as good antibacterial activity and the ability to compete with Salmonella Typhimurium for adhesion sites on Caco-2 cells. Our results indicate that L. plantarum A, B and S1 strains are promising candidates with probiotic properties.

\section{Acknowledgements}

This study was financially supported by the University of Rijeka, Rijeka, Croatia: initial support (13.06.2.2.60) and project (13.06.1.1.07), and AMAC-UK support.

\section{References}

1. Marteau PR, de Vrese M, Cellier CJ, Schrezenmeir J. Protection from gastrointestinal diseases with the use of probiotics. Am J Clin Nutr. 2001;73(2 Suppl):430S-6S.
2. Soccol CR, Vandenberghe LPDS, Spier MR, Medeiros ABP, Yamaguishi CT, De Dea Lindner J, et al. The potential of probiotics: a review. Food Technol Biotechnol. 2010;48:413-34.

3. Babić I, Markov K, Kovačević D, Trontel A, Slavica A, Đugum J, et al. Identification and characterization of potential autochthonous starter cultures from a Croatian 'brand' product 'Slavonski kulen'. Meat Sci. 2011;88:517-24. http://dx.doi.org/10.1016/j.meatsci.2011.02.003

4. Arena MP, Silvain A, Normanno G, Grieco F, Drider D, Spano G, Fiocco D. Use of Lactobacillus plantarum strains as a bio-control strategy against food-borne pathogenic microorganisms. Front. Microbiol. 2016;7:464. http://dx.doi.org/10.3389/fmicb.2016.00464

5. Health and nutritional properties of probiotics in food including powder milk with live lactic acid bacteria: Joint FAO/WHO Experts Consultation, October 2001. Geneva, Switzerland: Food and Agricultural Organization of the United Nations and World Health Organization (FAO/WHO): 2001. Available from: http://www.mesanders.com/probio_report.pdf.

6. Kaushik JK, Kumar A, Duary RK, Mohanty AK, Grover S, Batish VK. Functional and probiotic attributes of an indigenous isolate of Lactobacillus plantarum. PLoS ONE. 2009;4: e8099. http://dx.doi.org/10.1371/journal.pone.0008099

7. Herreros MA, Sandoval H, González L, Castro JM, Fresno JM, Tornadijo ME. Antimicrobial activity and antibiotic resistance of lactic acid bacteria isolated from Armada cheese (a Spanish goats' milk cheese). Food Microbiol. 2005;22:455-9. http://dx.doi.org/10.1016/j.fm.2004.11.007

8. Kos B, Beganović J, Jurašić L, Švađumović M, Leboš Pavunc A, Uroić K, Šušković J. Coculture-inducible bacteriocin biosynthesis of different probiotic strains by dairy starter culture Lactococcus lactis. Mljekarstvo. 2011;61:273-82.

9. Tejero-Sariñena S, Barlow J, Costabile A, Gibson GR, Rowland I. In vitro evaluation of the antimicrobial activity of a range of probiotics against pathogens: evidence for the effects of organic acids. Anaerobe. 2012;18:530-8. http://dx.doi.org/10.1016/j.anaerobe.2012.08.004

10. Šušković J, Kos B, Frece J, Beganović J, Leboš Pavunc A. Probiotic Concept - probiotics as food supplements and probiotics as biotherapeutics. Croat J Food Technol Biotechnol Nutr. 2009;4:77-84 (in Croatian).

11. Bernet MF, Brassart D, Neeser JR, Servin AL. Adhesion of human bifidobacterial strains to cultured human intestinal epithelial cells and inhibition of enteropathogens-cell interactions. Appl Environ Microbiol. 1993;59:4121-8.

12. Dimitrov Z, Gotova I, Chorbadjiyska E. In vitro characterization of the adhesive factors of selected probiotics to Caco-2 epithelium cell line. Biotechnol Biotechnol Equip. 2014;28: 1079-83. http://dx.doi.org/10.1080/13102818.2014.969948

13. Myllyluoma E, Ahonen AM, Korpela R, Vapaatalo H, Kankuri E. Effects of multispecies probiotic combination on Helicobacter pylori infection in vitro. Clin Vaccine Immunol. 2008;15:1472-82. http://dx.doi.org/10.1128/CVI.00080-08

14. Sribuathong S, Saengprakai J, Trevanich S. In vitro anti-adherent assessment of selected lactic acid bacteria isolates against Salmonella Typhimurium and Listeria monocytogenes to Caco-2 cells. J Food Saf. 2014;34:270-82. http://dx.doi.org/10.1111/jfs.12123

15. Woo TDH, Oka K, Takahashi M, Hojo F, Osaki T, Hanawa T, et al. Inhibition of the cytotoxic effect of Clostridium difficile in vitro by Clostridium butyricum MIYAIRI 588 strain. J Med Microbiol. 2011;60:1617-25. http://dx.doi.org/10.1099/jmm.0.033423-0.

16. Henson S. Estimating the incidence of food-borne Salmonella and the effectiveness of alternative control measures using 
the Delphi method. Int J Food Microbiol. 1997;35:195-204. http://dx.doi.org/10.1016/S0168-1605(96)01235-4

17. de Jong HK, Parry CM, van der Poll T, Wiersinga WJ. Hostpathogen interaction in invasive salmonellosis. PLoS Pathog. 2012;8:e1002933. http://dx.doi.org/10.1371/journal.ppat.1002933

18. Ouwehand A, Vesterlund S. Health aspects of probiotics. IDrugs. 2003;6:573-80.

19. Baccigalupi L, Di Donato A, Parlato M, Luongo D, Carbone V, Rossi M, et al. Small surface-associated factors mediate adhesion of a food-isolated strain of Lactobacillus fermentum to Caco-2 cells. Res Microbiol. 2005;156:830-6. http://dx.doi.org/10.1016/j.resmic.2005.05.001

20. Giannasca KT, Giannasca PJ, Neutra MR. Adherence of Salmonella typhimurium to Caco-2 cells: identification of a glycoconjugate receptor. Infect Immun. 1996;64:135-45.

21. Bishop A, House D, Perkins T, Baker S, Kingsley RA, Dougan G. Interaction of Salmonella enterica serovar Typhi with cultured epithelial cells: roles of surface structures in adhesion and invasion. Microbiology. 2008;154:1914-26. http://dx.doi.org/10.1099/mic.0.2008/016998-0

22. Bernet-Camard MF, Liévin V, Brassart D, Neeser JR, Servin AL, Hudault S. The human Lactobacillus acidophilus strain LA1 secretes a nonbacteriocin antibacterial substance(s) active in vitro and in vivo. Appl Environ Microbiol. 1997;63: 2747-53.

23. Coconnier MH, Liévin V, Lorrot M, Servin AL. Antagonistic activity of Lactobacillus acidophilus LB against intracellular Salmonella enterica serovar Typhimurium infecting human enterocyte-like Caco-2/TC-7 cells. Appl Environ Microbiol. 2000;66:1152-7. http://dx.doi.org/10.1128/AEM.66.3.1152-1157.2000

24. Servin AL. Antagonistic activities of lactobacilli and bifidobacteria against microbial pathogens. FEMS Microbiol Rev. 2004;28:405-40.

http://dx.doi.org/10.1016/j.femsre.2004.01.003

25. Walencka E, Różalska S, Sadowska B, Różalska B. The influence of Lactobacillus acidophilus-derived surfactants on staphylococcal adhesion and biofilm formation. Folia Microbiol. 2008;53:61-6. http://dx.doi.org/10.1007/s12223-008-0009-y

26. Lehto EM, Salminen SJ. Inhibition of Salmonella typhimurium adhesion to Caco-2 cell cultures by Lactobacillus strain GG spent culture supernate: only a pH effect? FEMS Immunol Med Microbiol. 1997;18:125-32. http://dx.doi.org/10.1111/j.1574-695X.1997.tb01037.x

27. Bilkova A, Kinova Sepova H, Bukovsky M, Bezakova L. Antibacterial potential of lactobacilli isolated from a lamb. Vet Med. 2011;56:319-24.

28. Lim SM, Im DS. Screening and characterization of probiotic lactic acid bacteria isolated from Korean fermented foods. J Microbiol Biotechnol. 2009;19:178-86. http://dx.doi.org/10.4014/jmb.0804.269

29. Travers MA, Florent I, Kohl L, Grellier P. Probiotics for the control of parasites: an overview. J Parasitol Res. 2011;2011: Article ID 610769. http://dx.doi.org/10.1155/2011/610769
30. Molin G. Probiotics in foods not containing milk or milk constituents, with special reference to Lactobacillus plantarum 299v. Am J Clin Nutr. 2001;73(2 Suppl):380S-5S.

31. Kumar A, Kumar D. Characterization of Lactobacillus isolated from dairy samples for probiotic properties. Anaerobe. 2015;33:117-23.

http://dx.doi.org/10.1016/j.anaerobe.2015.03.004

32. Frece J, Kos B, Beganović J, Vuković S, Šušković J. In vivo testing of functional properties of three selected probiotic strains. World J Microbiol Biotechnol. 2005;21:1401-8. http://dx.doi.org/10.1007/s11274-005-5741-8

33. National Salmonella Surveillance Overview. Atlanta, GA, USA: US Department of Health and Human Services, Centers for Disease Control and Prevention; 2011.

34. Mittrücker HW, Kaufmann SH. Immune response to infection with Salmonella typhimurium in mice. J Leukoc Biol. 2000;67:457-63. http://dx.doi.org/10.1186/1471-2334-7-65

35. Andino A, Hanning I. Salmonella enterica: survival, colonization, and virulence differences among serovars. Sci World J. 2015;Article ID 520179. http://dx.doi.org/10.1155/2015/520179

36. Neal-McKinney JM, Lu X, Duong T, Larson CL, Call DR, Shah DH, Konkel ME. Production of organic acids by probiotic lactobacilli can be used to reduce pathogen load in poultry. PLoS ONE. 2012;7:e43928. http://dx.doi.org/10.1371/journal.pone.0043928

37. Tejero-Sariñena S, Barlow J, Costabile A, Gibson GR, Rowland I. In vitro evaluation of the antimicrobial activity of a range of probiotics against pathogens: evidence for the effects of organic acids. Anaerobe. 2012;18:530-8. http://dx.doi.org/10.1016/j.anaerobe.2012.08.004

38. Millette M, Luquet FM, Lacroix M. In vitro growth control of selected pathogens by Lactobacillus acidophilus- and Lactobacillus casei-fermented milk. Lett Appl Microbiol. 2007;44: 314-9. http://dx.doi.org/10.1111/j.1472-765X.2006.02060.x

39. Kos B, Šušković J, Vuković S, Šimpraga M, Frece J, Matošić S. Adhesion and aggregation ability of probiotic strain Lactobacillus acidophilus M92. J Appl Microbiol. 2003;94:981-7. http://dx.doi.org/10.1046/j.1365-2672.2003.01915.x

40. Janković T, Frece J, Abram M, Gobin I. Aggregation ability of potential probiotic Lactobacillus plantarum strains. Int J Sanit Eng Res. 2012;6:19-24.

41. Greene JD, Klaenhammer TR. Factors involved in adherence of lactobacilli to human Caco-2 cells. Appl Environ Microbiol. 1994;60:4487-94.

42. Frece J, Kos B, Svetec IK, Zgaga Z, Beganović J, Leboš A, Šušković J. Synbiotic effect of Lactobacillus helveticus M92 and prebiotics on the intestinal microflora and immune system of mice. J Dairy Res. 2009;76:98-104. http://dx.doi.org/10.1017/S0022029908003737

43. Jankowska A, Laubitz D, Antushevich H, Zabielski R, Grzesiuk E. Competition of Lactobacillus paracasei with Salmonella enterica for adhesion to Caco-2 cells. J Biomed Biotechnol. 2008;2008:Article ID 357964. http://dx.doi.org/10.1155/2008/357964 